\title{
Does the pandemic help us make education more equitable?
}

\author{
Pasi Sahlberg ${ }^{1}$ \\ Received: 18 August 2020 / Accepted: 30 September 2020 / Published online: 31 October 2020 \\ (c) Springer Nature Singapore Pte Ltd. 2020
}

\begin{abstract}
Everybody agrees that the COVID-19 pandemic is a big disruption in education. It questions many traditional rules and structures that have organised the work of schools in the past. But not everyone agrees that the pandemic will eventually change schools. In this article, I narrow the scope of that question and ask whether the pandemic helps us fix some of the preexisting inequalities that we were unable, and often unwilling, to improve. I argue that as we think about how education should be reimagined, it is paramount to continue efforts to make education more inclusive, fairer and equitable for all. I take some early examples from two distinct education systems, Australia and Finland, to highlight how disrupted teaching caused by school closures has had different impacts on schools and teachers. The conclusion is that the pandemic may help make education more equitable if current socio-economic inequalities are addressed early on; teachers and principals are trusted more in leading schools forward in the post-pandemic world; and schools and children are supported to become more selfdirected in leading and learning.
\end{abstract}

Keywords COVID-19 $\cdot$ Equity $\cdot$ Inequality $\cdot$ Australia $\cdot$ Finland

\section{The unexpected disruption}

Many education systems were in trouble already before the coronavirus disease (COVID-19) became a global pandemic on 11 March 2020. In its first ever Human Development Report in 2018 that was devoted entirely to education, the World Bank (2018) announced a global learning crisis that, among many other things, amplified educational inequalities because "it severely hobbles the disadvantaged youth who most need the boost that a good education can offer" (World Bank 2018, p. 6). The OECD's Programme for International Student Assessment (PISA) 2018 found out that the performance difference on average across the OECD countries between the $10 \%$ most socio-economically advantaged and the $10 \%$ most disadvantaged students in reading literacy test was 141 points, that is equivalent to more than three years of schooling (OECD 2019). OECD concluded that "there has also been no real overall improvement in the learning outcomes of students in OECD countries, even though expenditure on schooling rose by more than $15 \%$ over the past decade alone" (OECD

$\bowtie$ Pasi Sahlberg

Pasi.Sahlberg@unsw.edu.au

1 University of New South Wales - Gonski Institute for Education, Sydney, NSW 2052, Australia 
2019, p. 5). UNESCO's Global Education Monitoring Report 2020 stated that according to the estimates before the COVID-19 pandemic, globally, one-sixth, or 260 million children, adolescents and youth were not attending school (UNESCO 2020a). Only three quarters of 15 -year-olds in middle-income countries are still in school, and even those students achieve just half the basic level of proficiency required.

In August 2020, the United Nations Secretary-General António Guterres said, "Now we face a generational catastrophe that could waste untold human potential, undermine decades of progress, and exacerbate entrenched inequalities" (UNESCO 2020b). One reason is that those children who need school more than others for learning and well-being can't go to school or have insufficient access to teaching support in other ways. According to the UN's predictions, 24 million learners are at risk of dropping out of school. Another reason that has been common in every country to some extent is limited access to the digital learning from home or lack of capacity of schools to integrate digital technologies in remote teaching and learning.

We don't know yet exactly how the disruption of normal schooling has affected children's education. Early results published in different parts of the world have revealed two important issues. Shift to remote teaching and learning when children were not able to go to school has (a) exposed and often amplified the existing social and educational inequalities, and (b) underlined the importance of ongoing individualised support to children with special educational needs as part of teaching (Australian Academy of Science 2020; Graham and Sahlberg 2020; Finnish Education Evaluation Centre 2020; Noble 2020). It is understandable that there are notable differences between and even within education systems, in terms of how teachers and schools adjusted to that disrupted schooling. It is too early to say how education systems have managed to cope with these new arrangements and how these different remote learning arrangements have affected students' learning and well-being.

\section{We are all in this together}

According to the evidence around the world, income inequality is a growing social phenomenon in many countries (Piketty 2017; Wilkinson and Pickett 2018). This means that the rich are getting richer and the poor are getting poorer. It also means that having an education system that would provide each child fair and inclusive opportunity to good school is becoming increasingly difficult. The proportion of children living in poverty that is strongly associated with income inequality ranges from about 5 per cent in the Nordic countries to over 20 per cent in the USA and Israel, according to the OECD database. At the same time, growing evidence base shows that equity and quality of student outcomes at the level of education systems are positively related to one another (OECD 2018; Parker et al. 2018). In other words, most successful education systems are those that combine equity and excellence in their education policies and practices. This is why growing inequality in education is bad news not just to those who suffer from the lack of fairness and inclusion, but to the entire society.

Public institutions have a paramount role to play in preventing and coping with the negative consequences of socio-economic inequalities. Public schools have been critically important in providing equal educational opportunities to children from the wide range of social classes in Finland, Australia and the rest of the world. There are many children in these countries who need their school and teachers more than others to succeed in learning and life. There are also those who learn well and perhaps even better without going to school. What is good 
for one student may not be good for some others. What the COVID-19 pandemic has made clear is that some children need teachers more than others do. The inability to understand this and effectively respond to these individual needs is one big reason for the current inequities in education.

How these inequalities affect educational achievement requires an understanding of how much schools matter in what students are supposed to learn there. No doubt schools are very important. As we have seen during interrupted face-to-face teaching in many countries, there are many students who struggle to keep going on learning without being taught by teachers at school. An important question, however, is how much of the variation of student academic performance is due to these in-school factors, such as teachers, leadership, curriculum, schedules and educational facilities. Since the landmark study by James Coleman and colleagues in 1966, research on school effectiveness has shed light on this question in different education contexts (Coleman et al. 1966). The common view is that in-school factors explain up to onethird of that variation and that the influence of all factors outside the school gate is estimated to be about 60 per cent (Haertel 2013). The rest is what could be called unexplained variation. If it is true that schools account for about a third of the variability in student test scores, then the best opportunities for improving the quality of education outcomes are in developing the system-level conditions, including those in other public sectors that can positively affect the lives of children.

Equitable education often means that differences in learning outcomes in school "are not the result of differences in wealth, income, power or possessions" (Australian Government 2011). UNESCO (2018) sees equity in education as the means to achieving equality by making sure that all students have best possible opportunities to grow into their full potential. Similarly, OECD states that education is equitable when "differences in students' outcomes are unrelated to their background or to economic and social circumstances over which the students have no control" (OECD 2018). It has been well known prior to the pandemic that inequalities related to socio-economic status, education attainment, access to adequate education, gender, domicile and student characteristics have been some major causes of differences in student achievement in school. In brief, the more inequalities there are in the education system, the less equitable that education system becomes.

Various inequalities in school systems that have been exposed by the COVID-19 pandemic are often due to a complex set of social, cultural and economic conditions rather than educational factors alone. Good teachers will continue to be the most important in-school solution to address these inequalities in systematic ways in post-pandemic schooling. But since the pandemic has also amplified the implications of socio-economic inequalities in students' opportunities to learn successfully, interventions by other public sectors to support these children are essential. These solutions and actions after the pandemic to combat unfairness and exclusion in education will need to be different from country to country and even within countries. Let's look at two examples from different sides of the world and how the disruption caused by the COVID-19 has affected teaching and learning.

\section{Fire and ice}

Australia and Finland, the two homes of mine at the moment, are not just geographically as distant from each other than possible, but they are also very different societies with distinct histories, traditions, values and cultures. Australia is sunny and hot. Finland is, many believe, snowy and cool. The Australians prefer things big and fast. The Finns think small is beautiful. 
In other words, Australia is fire, Finland is ice. These cultural distinctions make education in these two countries and how each react to external shocks such as the current pandemic, very different from each other. Here is how.

Most school facilities were closed for majority of primary and secondary school students in Finland starting March 18 until May 14 this year due to the government's measures to prevent the spread of the COVID-19 pandemic. Early childhood and care centres (kindergartens) remained open and children of essential workers and those with severe special educational needs in first three grades of primary schools had an opportunity to attend school if parents so preferred. During the remote learning phase, one-third of children were in kindergartens and less than 10 per cent of all basic school (grades 1 to 9) students went to school as usual. Since education governance in Finland is decentralised and 310 local authorities run and, to a large extent, also fund the schools, these authorities were responsible for the practical execution of the transition from face-to-face teaching in schools to remote distance learning mode from homes. After the remote learning period in mid-May was over almost 90 per cent of school children returned to school and more than half of children in early childhood education and care were back for the last two weeks of May before their summer holidays.

The speed and scale of disruption came as a surprise to Finnish schools as it did to others around the world. Before March some schools had prepared emergency strategies for minor situations, but no one was prepared to such a massive external crisis as the COVID-19 pandemic. However, Finnish schools had two particular positive features on their side in shifting literally overnight from contact teaching at school to remote learning from home. First, according to the Finnish National Agency for Education (2020), three quarters of Finnish schoolteachers at the time of the (partial) school closures had digital teaching and learning facilities available in their schools. Vast majority of teachers were also familiar with using these facilities in teaching, although the confidence to do that well varied from school to school.

Second, the National Core Curricula that is the foundation for schools' own curriculum planning have emphasised self-directed learning through projects and real-life problemsolving that have made many students familiar with independent study and self-assessing their own learning (Sahlberg 2021). Again, there are differences from school to school in how successful this practice has been. Teachers have been mostly concerned about those children who require more direct support in their learning that has been not so easy to arrange through virtual arrangements.

Early research findings shed light on how children, teachers and parents or guardians have experienced interrupted schooling in Finland. A large national study that is currently underway by the Universities of Helsinki and Tampere is exploring how remote teaching and learning in Finnish schools went from principals', teachers', parents' and children's perspectives (Ahtiainen et al. 2020). The first findings in this study confirm the anecdotal evidence gained during April and May, as well as trends found in other surveys. According to about half of 860 principals and little less than half of over 5000 teachers who took part in this study, students with special educational needs were not receiving appropriate support from teachers and schools during the remote learning period, compared with normal times previously. Approximately a quarter of students $(N=56,000)$ and over 40 per cent of parents $(N=36,000)$ believed that they received less support from their school while they were learning from home, than what they would have received in school previously. About one in five lower secondary school students said that they had difficulties with technology or internet connectivity, and the same proportion of students confessed they stayed up too late every night with digital gadgets or social media. 
A closer look at how students have experienced the school closures reveals an important finding. Whereas authorities and other adults are afraid that children will stop learning or that there will be losses in their lifetime earnings, not all children seem to think like this. In Finland, for example, over 60 per cent of 10- to 16-year-old students said that they enjoyed learning remotely most of the time and that most of them learned at least the same "amount" or even more compared to what they thought they had learned at school (Ahtiainen et al. 2020). If these tens of thousands of students are right, then perhaps we need to rethink what we mean by learning and how it should be measured and recognised at school.

The COVID-19 pandemic has affected Australian education systems in different ways. School buildings were closed for varying periods of time after the first school term break in April. Remote learning arrangements lasted from one week in Northern Territory and South Australia, to nine weeks in Victoria (that has the second interruption of schooling at the moment of writing). School education in Australia is, in general, more centralised and governed by common standards compared to Finnish education system. Teaching and learning are influenced by frequent standardised tests (such as NAPLAN) and school-leaving examinations that often narrow the role of teachers and students, when it comes to the assessment of student learning. Not surprisingly, one prominent discourse in the media and among many parents has been the question of how the negative impact of remote learning on students" test score and examination results could be mitigated. Various "catching up" measures have been suggested to do that, especially for disadvantaged students who are thought to lose the most in these measurements.

Compared to Finland, Australia's education system as a whole has two interrelated features that makes it more fragile to sudden external shocks like the COVID-19 pandemic. First, one-third of students in Australia attend non-government schools that are independently governed and often better resourced than many government schools. Vast majority of at-risk students attend government schools. Second, inequality is more prevalent in Australian school system compared to Finland and many other OECD countries. For example, performance gap between the highest and lowest deciles in OECD's PISA 2018 survey was significantly wider in Australia (OECD 2019). Furthermore, disadvantaged students are often concentrated into disadvantaged public schools that is harmful for equitable outcomes at the level of the education system.

Early results of a large national survey of 10,000 teachers in Australia reveal similar but also different reactions in schools to disrupted teaching and learning, compared with what has been reported in Finland (Wilson et al. 2020). Similar to Finland, four of five teachers were worried about their students with special educational needs. Just about a quarter of teachers thought they were confident that students were learning well under remote learning arrangements and just over 40 per cent were confident that the majority of their students were positively engaged with online learning. Only one-third of Australian teachers felt satisfied with assessment during remote learning compared to 95 per cent of teachers in Finland who said they were able to assess students' learning when they were learning from home.

The Grattan Institute in Australia concluded that the most disadvantaged students suffered the most during school closures (Sonnemann and Goss 2020). "Disadvantaged students often have a home environment that is not conducive to learning and get less help from parents compared to their advantaged peers" (p. 9), according to their report on the impacts of COVID-19 on school education. Poorer internet access, fewer digital devices and lack of quiet place to study at home were often the common factors in disadvantaged homes.

The culture of schools in Australia is much more about conformity where schools often are compliant rather than creative in responding to sudden changes in their environments. National assessment programme for literacy and numeracy (NAPLAN) in primary and sec- 
ondary schools serves as a yardstick to compare schools' performance with one another. But it also amplifies the existing educational inequities when parents who can afford to pay for education can choose the school with higher NAPLAN scores (and often more affluent student socio-economic make-up) for their children. Interestingly, when NAPLAN tests were cancelled this year due to school closures, some parents were concerned about how they would know what their children have learned at school. Most teachers, however, according to Wilson et al. (2020), were more worried about students' health and well-being. Uncertainty of the future of national assessments in Australia raises questions of whether schools should focus on "catching up" to be prepared for the next year's tests, or care more about children's well-being and health during the pandemic, even though their learning progress may be affected.

\section{Mission possible}

The COVID-19 pandemic has exposed and often amplified the existing inequalities in education system across the world. It is common knowledge that not all children have access to educational online resources and that how children are taught to study with digital technologies varies greatly from one school to another. Most importantly, research has shown that only a minor part of the variation of measured student achievement in school is associated with in-school factors, such as teachers, principals or curricula (Haertel 2013). Therefore, if most of that variation can be explained by factors outside the school gate, should the efforts to strengthen equity in education target more on fixing inequalities that affect children outside the school?

No doubt there will be piles of studies that will show how different education systems managed to navigate through the current global pandemic. There will be those that struggled and those that did much better than others. First, comparative lessons revealed that education systems that are built on trust-based professionalism, that have flexibility and autonomy to adapt curriculum to local needs and strengths, that can adjust teaching and learning to changing circumstances, and that rely less on externally measured standards seem to have had an easier time during the first wave of the pandemic (OECD 2020). Time will probably also tell that more equitable societies and education systems go through these difficult times with less harm to students and their families.

Prevention is always a smarter strategy than cure. This will hopefully be another lesson from the COVID-19 pandemic. A one-off "catch-up" intervention for disadvantaged students for six months from July to December 2020 in Australia was estimated to cost 1.2 billion Australian dollars, or 900 million US dollars (Sonnemann and Goss 2020). The cost of educational inequality can be huge, and another catch-up may have to be implemented again if the root cause is not addressed. Now will be a good time to think how educational equity could be better achieved. One way to do that is to take a closer look how more equitable education systems have done it. Here are three principles to consider.

Addressing inequalities early. One of the most powerful ways to strengthen equity in education is to avoid inequalities in early childhood. Preventive healthcare and high-quality early childhood education and care are the most common ways to make sure that more children will be ready to learn at school. Early intervention policies to help children "catch up" during teaching and learning can effectively reduce performance gaps between students.

Trusting teachers as professionals. The COVID-19 pandemic revealed an interesting dilemma in many countries: Should teaching during remote arrangements focus more on 
core subjects, i.e. literacy and numeracy, and prepare students for future tests and examinations, or should it address more social and emotional well-being and holistic learning of competences needed in real life? In exceptional and uncertain circumstances, the best answer to this question comes from those who are closest to the action, in this case the teachers. Schools can better include policies and action into their work when teachers and principals are treated as trusted professionals in deciding what is best for all children.

Building self-directedness. Schools are often at the bottom of educational food chains. They comply with dozens of rules and regulations to satisfy a range of external expectations. Teachers and students often follow similar modus operandi in classrooms. An important lesson from the COVID-19 pandemic is that schools and students who are more self-directed in their own teaching and learning often do better in both normal and crisis situations, than those who haven't learned to do so. Self-directedness strengthens student engagement, brings about authentic learning and helps schools respond better to emerging inequalities.

This global pandemic has shown that school is more than a place of knowledge acquisition. School is part of the social fabric that has reciprocal relationships with social, health, cultural and economic aspects of life. Making education systems more equitable requires a better understanding of the complexity of schooling as part of our increasingly fragile societies.

Does the pandemic help make education more equitable? It is most likely that the pandemic will cause huge dents in national budgets around the world and make any change in education that requires more money unrealistic. Governments will probably switch to the austerity mode that will force schools to do more with less. That will probably keep the old ways of measuring schools' performance as they were before the pandemic, rather than actively reform the education system with better ways to monitor educational progress.

There is a chance, however, that something else would happen instead. That requires both government leaders and parents to understand what equity in education is and why it is an important feature of inclusive and high-quality schooling. That also requires everyone in the society to understand that we don't need to accept inequality in education in order to achieve excellence, as many might have done before. Finland is a good example of a country where educational excellence has been achieved through greater equity (Sahlberg 2021). Only when the society in general accepts this view and realises that equitable education can benefit all, not just some, of us, will there be significant and sustainable improvement in our school systems. One of the early champions of educational equity Ron Edmonds (1979, p. 23) said, "We can, whenever and wherever we choose, successfully teach all children whose schooling is of interest to us. We already know more than we need to do this. Whether we do it or not must finally depend on how we feel about the fact that we have not done it so far".

\section{References}

Ahtiainen, R., Asikainen, M., Heikonen, L., Hienonen, N., Hotulainen, R., Lindfors, P., Lindgren, E., Lintuvuori, M., Oinas, S., Rimpelä, A., \& Vainikainen, M-P. (2020). Koulunkäynti, opetus ja hyvinvointi kouluyhteisössä koronaepidemian aikana. Ensitulokset. University of Tampere/University of Helsinki. Unpublished preliminary report.

Australian Academy of Science (2020). Differential learning outcomes for online versus in-class education. Rapid Research Information Forum. Retrieved from: https://www.science.org.au/covid19/learningoutcomes-online-vs-inclass-education

Australian Government (2011). Review of funding for schooling. Final report. Canberra: Department of Education, Employment and Workplace Relations.

Coleman, J., Campbell, E., Hobson, C., McPartland, J., Mood, A., Weinfeld, F., \& York, R. (1966). Equality of educational opportunity. Washington, DC: Government Printing Office.

Edmonds, R. (1979). Effective schools for urban poor. Educational Leadership, 37(1), 15-24. 
Finnish Education Evaluation Centre (2020). Poikkeuksellisten opetusjärjestelyjen vaikutukset tasaarvon ja yhdenvertaisuuden toteutumiseen. Retrieved from: https://karvi.fi/app/uploads/2020/05/ Poikkeuksellisten-opetusjärjestelyjen-vaikutukset-osa-I-Karvi-7.5.2020-1.pdf

Graham, A. \& Sahlberg, P. (2020). Schools are moving online, but not all children start out digitally equal. The Conversation, March 26.

Haertel, E. H. (2013). Reliability and validity of inferences about teachers based on student test scores. Princeton, NJ: Educational Testing Service.

National Agency for Education. (2020). Valtakunnallisen oppimateriaalikyselyn 2019 tuloksia. Faktaa Express 2A/2020. Retrieved from https://www.oph.fi/fi/uutiset/2020/opetushallituksen-kysely-tarjoaa-kattavankuvan-oppimateriaalitilanteesta-juuri-ennen

Noble, K. (2020). COVID-19 school closures will increase inequality unless urgent action closes the digital divide. Mitchell Institute. Retrieved from https://www.mitchellinstitute.org.au/opinion/covid19-digitaldivide/

OECD. (2018). Equity in education. Breaking down barriers to social mobility. Paris: OECD.

OECD. (2019). PISA 2018 results. What students know and can do (Vol. 1). Paris: OECD.

OECD (2020). Learning remotely when schools close: How well are students and schools prepared? Insights from PISA. OECD Policy Responses to Coronavirus (Covid-19). Retrieved from: https://www.oecd.org/ coronavirus/en/\#policy-responses

Parker, P., Marsh, H., Jerrim, J., Guo, J., \& Cicke, T. (2018). Inequity and excellence in academic performance: Evidence from 27 countries. American Educational Research Journal, 55(4), 836-858. https://doi.org/1 $0.3102 / 0002831218760213$.

Piketty, T. (2017). Capital in the Twenty-first century. The Belknap Press of Harvard University Press.

Sahlberg, P. (2021). Finnish lessons 3.0: What can the world learn from educational change in Finland. New York: Teachers College Press.

Sonnemann, J. \& Goss, P. (2020). COVID catch-up: helping disadvantaged students close the equity gap. Grattan Institute. Retrieved from: https:/grattan.edu.au/wp-content/uploads/2020/06/COVID-Catch-upGrattan-School-Education-Report.pdf

UNESCO. (2018). Handbook on measuring equity in education. Montreal: UNESCO Institute for Statistics.

UNESCO. (2020). Global education monitoring report. Inclusion and education: All means all. Paris: UNESCO.

UNESCO (2020). Press Release No. 2020-73, August 4. Retrieved from https://en.unesco.org/news/secretarygeneral-warns-education-catastrophe-pointing-unesco-estimate-24-million-learners-risk

Wilkinson, R., \& Pickett, K. (2018). The inner level. How more equal societies reduce stress, restore sanity and improve everyone's well-being. New York, NY: Allen Lane.

Wilson, R., McGrath-Champ, S., \& Mude, W. (2020). Preliminary results from a survey of remote learning arrangements during COVID-19. University of Sydney: Unpublished paper.

World Bank. (2018). World development report 2018. Learning to realize education's promise. Washington, DC: The World Bank.

Publisher's Note Springer Nature remains neutral with regard to jurisdictional claims in published maps and institutional affiliations. 